\title{
Design of Digital Map based on Hand Gesture as a Preservation of West Java History Sites for Elementary School
}

\author{
Ayung Candra Padmasaria,1,*, Yona wahyuningsih ${ }^{\mathrm{a}, 2}$, R. Deti Rostika ${ }^{\mathrm{a}, 3}$ \\ ${ }^{a}$ Universitas Pendidikan Indonesia, Bandung, Indonesia \\ ${ }^{1}$ ayungcandra@ upi.edu; ${ }^{2}$ yonawahyuningsih@ upi.edu; ${ }^{3}$ derosti@upi.edu
}

\begin{tabular}{|c|c|}
\hline Article Info & ABSTRACT \\
\hline $\begin{array}{l}\text { Article history: } \\
\text { Received: July 12, } 2019 \\
\text { Revised: August 14, } 2019 \\
\text { Accepted: August 27, } 2019\end{array}$ & $\begin{array}{l}\text { Social science study of historical content at present does not seem to be directly } \\
\text { proportional to the development of the industrial revolution } 4.0 \text {. it is because of rote } \\
\text { learning styles, text-based, teacher-centered teaching methods without technological- } \\
\text { aided modifications. With these problems, it is necessary to have design innovations } \\
\text { and media for learning models, one of them is to design a hand gesture-based map } \\
\text { equipped with a leap motion controller. This study aims to design a digital hand } \\
\text { gesture-based map design as the preservation of West Java historical sites for } \\
\text { elementary school children. The method used in the study is Design and Development } \\
\text { (D\&D). The results of this study are the design of anteractive map as teaching } \\
\text { media innovation and the configuration response of the tool with the results of } 13 \mathrm{~ms} \mathrm{/} \\
\text { FPS } 33 \text { ms / } 60 \text { FPS tap gesture responses. }\end{array}$ \\
\hline
\end{tabular}

\section{INTRODUCTION}

In the industrial revolution of 4.0 era, the flow of globalization has been unstoppable. In Indonesia, it proven by the development of increasingly sophisticated technology that emphasizes the patterns of the digital economy, artificial intelligence, big data, and robotic. This era is often called the phenomenon of disruptive innovation [1], [2]. In line with this, changes can have an impact on education. The existence of needs that are all packaged digitally requires teachers and educators to adapt to these changes.

There are five important elements that must be considered and will be implemented to encourage economic growth and national competitiveness in the Industrial Revolution 4.0 era. One of them is preparation of more innovative learning systems in universities [3] such as adjusting learning curricula, and improving students' abilities in terms of Data Information Technology (IT), Operational Technology (OT), Internet of Things (IoT), and Big Data Analytic. This will have an impact on college graduates who can integrate physical objects (digital and human), competitive and skilled, especially in the aspects of data literacy, technological literacy, and human literacy.

Breakthroughs in research and innovation can increase industrial productivity and enhance the renewal of technologybased education. One important thing in efforts to improve the quality of education is in the field of educational technology. AECT Task Force (1977) said that educational technology is a complex and integrated process involving many people, various procedures, ideas, tools, and organizations, to analyze various problems and implement, evaluate, manage problemsolving related to human learning activities.

One of the technological developments is multimedia which can change one's way of learning which is more interactive [4].The relationship between humans as user and computers (software/applications/ products) in certain file formats. The multimedia system used in this research is a hand gesture-based digital map. Gesture technology products for hand movement models can be grouped into two general definitions [5], the first is gesture (hand) as a representation of the movements of characters in the game, second is a gesture as a controller and user of an application/system. Gestures that are equipped with a built-in leapmotion controller are 
translated and detected in one hand and support the direct movement of the mouse and cursor by controlling the display of the monitor by using gestures for finger points [6]. It is expected that it will be easier to attract students' interest and success in learning, in order to obtain more enjoyable learning and eliminate the boring impression especially on social studies learning history material.

Social studies in learning history material with rote learning style, text-based, teacher-centered teaching methods without technological-assisted modifications, resulting in students not mastering the concepts. As with the historical material in social studies at elementary school grade 4 semester 1 , there are two items which are quite a lot which are local historical relics (around districts and provinces) and their preservation efforts. Social studies learning in historical material is still low with an indication that the learning process that has been implemented has been less successful in providing historical heritage concepts. If the teacher continues to use the method, students will experience difficulties in understanding the concept of social studies subjects, and the quality will be low. The use of hand gesture-based digital maps can be one way to improve comfort in the process of interaction between humans and machines, even more so when the interaction model (hand gestures) presented is based on 3dimensional space. Learning the history of preservation content from the past is also interesting to be presented to students.

Based on the problems, it needs a design and technology design as a novel effort in learning and preserving the historical heritage that must be mastered by elementary school children formed as a hand gesture-based digital map.

\section{LITERATURE REVIEW}

\section{A. Hand Gesture Understanding}

Human interaction and communication with machines through the use of gestures can be one way to increase convenience [7]. Even more, if the interaction model presented is based on 3-dimensional space. Gesture understanding for the model of hand movements can be grouped into two general definitions, the first is gesture (hand) as a representation of the movement of characters in the game, second is a gesture as a controller and user of an application/system. For example, when someone wants to start a system or application using a mouse or keyboard, this process can be replaced in gestures that give the same purposes. One example is the use of tap gestures, swipe gestures and so on. So this depends on the definition that applied to a system.

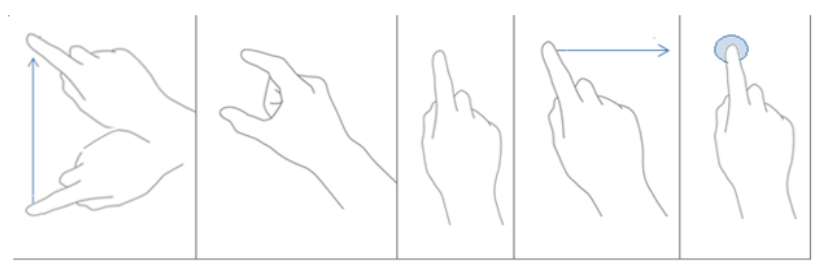

\section{B. Leap Motion Controller}

Leap Motion is a flashdisk-sized USB device that allows users to control a PC or notebook by using the movement of 10 fingers so there is no need to use a mouse. This device was developed by David Holz and Michael Buckwald. Their purpose in making leap motion is to change the function of the keyboard and mouse, allowing users to apply the computer only with the movements of their fingers.

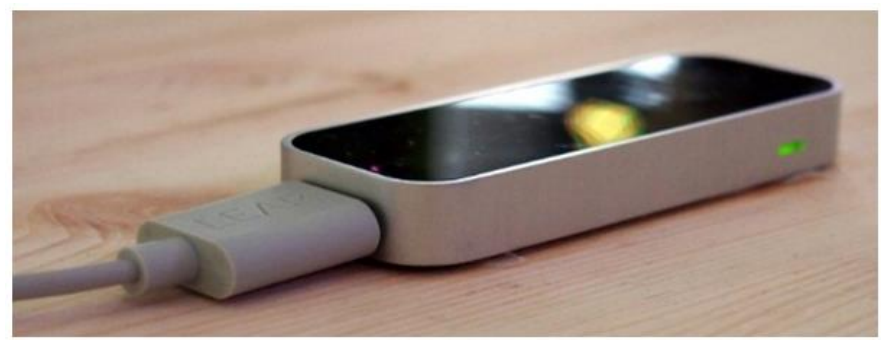

Fig. 2. Leap motion controller

The way Leap Motion works is by creating an interactive 4 cubic foot space that is able to detect fingers, hands and arm movements. Leap Motion can not only detect hand movements but a pencil or chopstick movements. Leap Motion has precision derived from data provided from Motion leap cameras having more hidden data that must be resolved in an RGB color space with a sharpness of $0.01 \mathrm{~mm}$ so it is not too far from the infrared wavelength. Here the user not only talk about pixels, but the only frequency, where the resolution space and information to be calculated is the frequency domain after Fourier Transform. Leap Motion software detects the hands, fingers by recording the position of the hands in the frame rate that is in Leap Motion.

\section{METHOD}

The data obtained from various sources that can support this digital map design. The data collection can be obtained through: (1) Identifying Phenomena and Problems, (2) Existing studies and studies of innovation models in history learning, and (3) Literature studies and related theories.

Referring to the purpose of this study, which is designing a hand-based Digital Map as a Preservation of historical sites, the research design used is D\&D research. It has two characteristics, which produce: (1) products in the form of artifacts; and (b) products are produced through a research process. The D\&D research implementation involves 3 stages that showed in Figure 3.

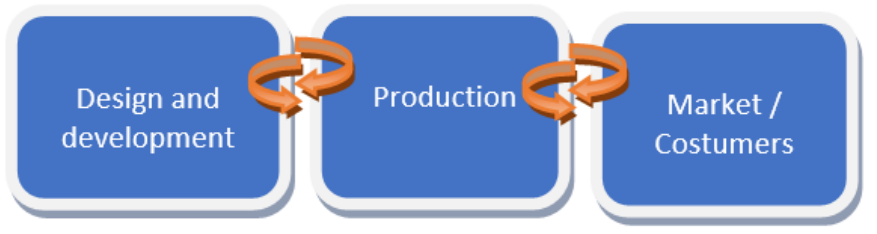

Fig. 3. D\&D research design

Fig. 1. Gesture motion 
The research design is based on (1) Market/Costumers related to the potential, problems, and needs, (2) Production, and (3) Design and Development. Figure 4 represents the statements.

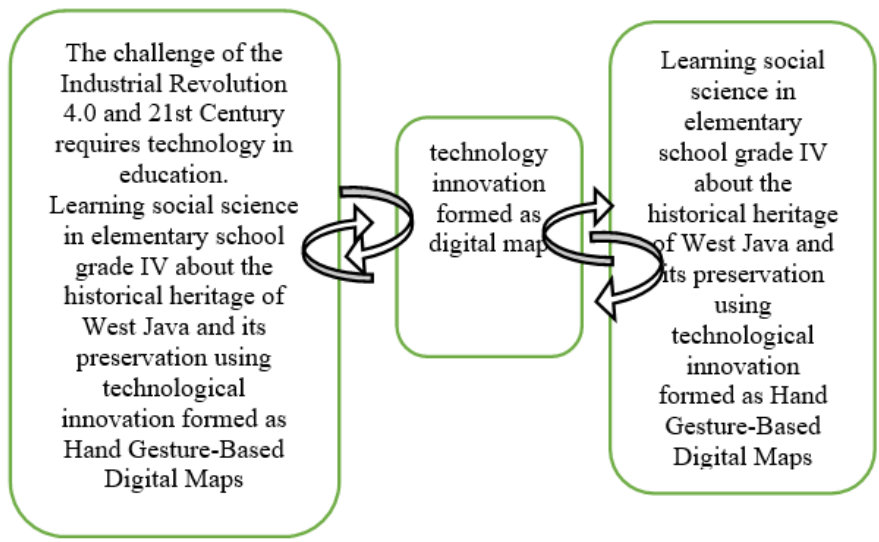

Fig. 4. D\&D research flow

\section{RESULT AND DISCUSSION}

\section{A. UI Design in a Touch Script}

Pan Gesture is done by touching the screen and moving a finger then sliding the finger in the direction desired, this process is used in the design of the scene in arranging and changing the position of the icon area selection. Figure 5 shows the flowchart of pan gesture.

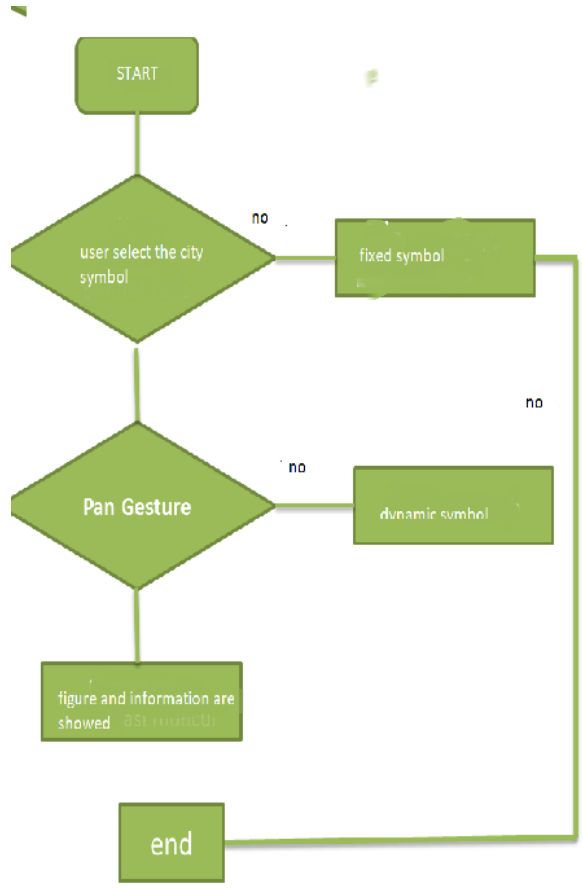

Fig. 5. Pan gesture flowchart

\section{B. System Design}

Hand gesture-based digital maps as interactive digital maps designed for site history information in West Java. The demand is based on elementary school students that need a presentation in an interactive and innovative way. It also as one of the references in the preservation of sites in West Java. Hand gesture-based digital maps are designed to have the following uniqueness:

- It contains information about Historical Sites in West Java. In this study, a sample of 11 cities with imaginative display designs was taken with the concept of adventure with choosing cities in West Java.

- User friendly and easy to use because of adapting from the windows $8 \mathrm{UI}$

Related to regional mapping, site locations in 11 West Java cities are designed in a neat arrangement based on categories and subcategories. The concept is expected to provide a more innovative appearance in promoting the excellence and local potential of the West Java region. The content presented is the contribution of various literature that are collected and processed into digital maps. An interactive, packaged media design has basic elements may consist of

- User Experience, is how a product behaves towards someone and that person gets feedback like pleasure and satisfaction from what he has done whether it is holding or touching[8].

- Interaction design, process of media is built based on identifying the need to meet user experience. Then, develops the design so it can communicate and be valued. For later evaluation will be obtained when the user experience process is offered [9].

- Usability goals interactive media have a reference that must be achieved when the product has been produced including effectiveness, efficiency, safety, utility, learnability, and Memorability[10].

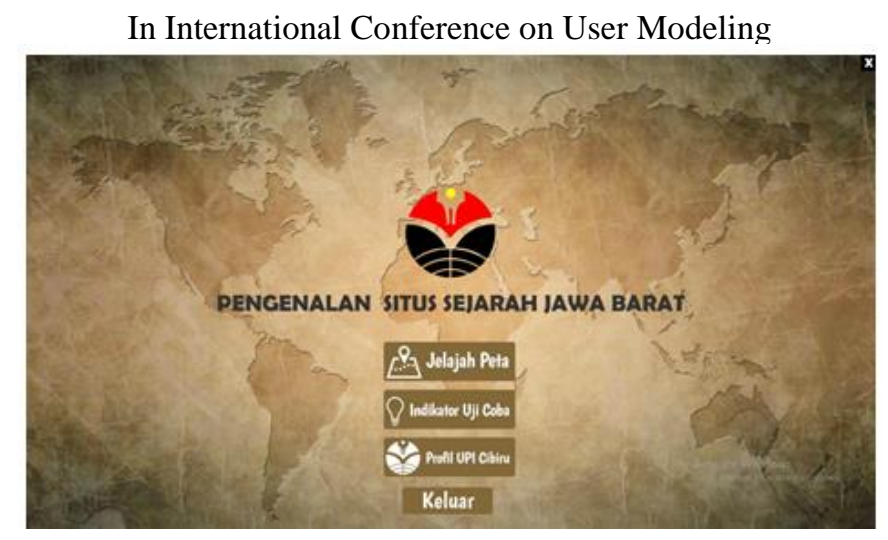

Fig. 6. Main preview of application

From Figure 6, it can be seen the main preview of application. Each navigation key in the picture is described as follows: 
- Map Browse button which contains the city selection menu in West Java depicted in the form of a map sketch. Each piece of map sketch has the contents of the material along with the image of the site in accordance with their respective sites

- Test indicator button to display indicator information and media functions in learning. The button is equipped with the way to use learning, both for individuals and classroom utilization.

- The UPI Cibiru profile contains information and identity of the UPI Cibiru campus and the media design team

Next, the example of map sub menu display in one region in West Java can be seen in Figure 7 and 8. In addition, for the configuration result is presented in Table 1 .

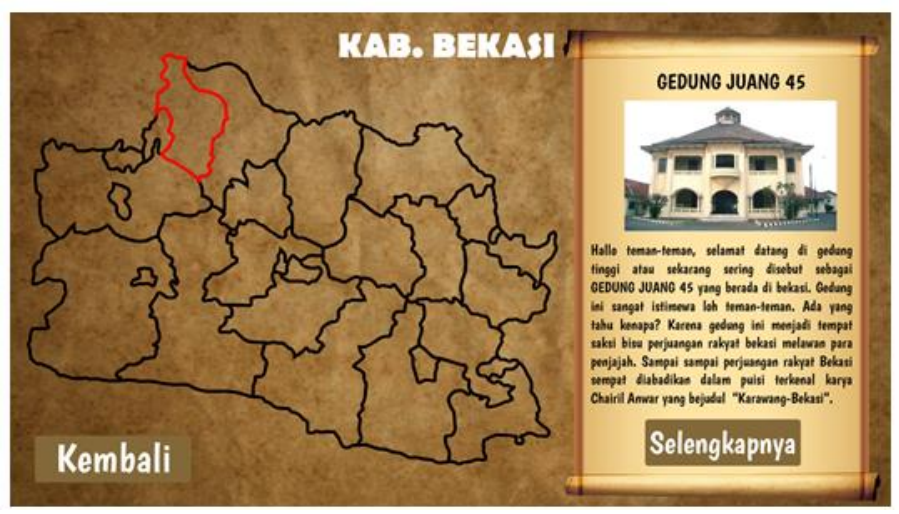

Fig. 7. Sub menu content preview
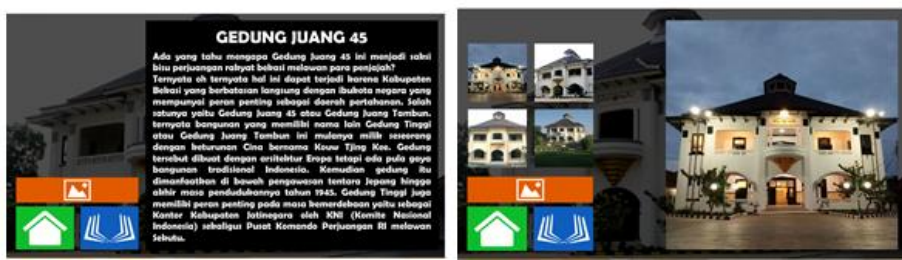

Fig. 8. Sub menu gallery preview

TABLE I. RESULT OF GESTURE RESPONSE EACH SCENE

\begin{tabular}{|c|c|c|c|}
\hline No. & Description & Response & Result \\
\hline 1 & $\begin{array}{l}\text { Tap gesture for } \\
\text { scene intro and } \\
\text { navigation buttons }\end{array}$ & $\begin{array}{l}13 \mathrm{~ms} / \mathrm{FPS} \\
33 \mathrm{~ms} / 60 \\
\text { FPS }\end{array}$ & Success \\
\hline 2 & $\begin{array}{l}\text { Tap gesture for map } \\
\text { selection }\end{array}$ & $\begin{array}{l}13 \mathrm{~ms} / \mathrm{FPS} \\
33 \mathrm{~ms} / 60 \\
\text { FPS }\end{array}$ & Success \\
\hline 3 & $\begin{array}{ll}\text { Tap Gesture trial } \\
\text { indicator and UPI } \\
\text { Cibiri profile }\end{array}$ & $\begin{array}{l}13 \mathrm{~ms} / \mathrm{FPS} \\
33 \mathrm{~ms} / 60 \\
\text { FPS }\end{array}$ & Success \\
\hline
\end{tabular}

\section{CONCLUSION}

The innovative learning media in social science learning about history has been developed. The product is formed as digital map based on hand gesture.

\section{References}

[1] C. M. Christensen, H. Baumann, R. Ruggles, and T. M. Sadtler, "Disruptive innovation for social change," Harv. Bus. Rev., vol. 84, no. 12, pp. 94-101, 2006.

[2] C. M. Christensen, M. E. Raynor, and R. McDonald, "What is disruptive innovation," Harv. Bus. Rev., vol. 93, no. 12, pp. 44-53, 2015.

[3] D. Charles, "Universities as key knowledge infrastructures in regional innovation systems," Innov. Eur. J. Soc. Sci. Res., vol. 19, no. 1, pp. 117-130, 2006.

[4] R. E. Mayer, "Using multimedia for e-learning," J. Comput. Assist. Learn., vol. 33, no. 5, pp. 403-423, 2017.

[5] A. Hamza, R. Anand, P. Shivhare, and A. Gaurav, "International Journal of Interdisciplinary Research," Hand Gesture Recognit. Appl., vol. 13, pp. 2073-2075, 2017.

[6] K. Sabir, C. Stolte, B. Tabor, and S. I. O’Donoghue, "The molecular control toolkit: controlling 3D molecular graphics via gesture and voice," in IEEE Symposium on Biological Data Visualization (BioVis), 2013, pp. 49-56.

[7] B. Yoo et al., "3D user interface combining gaze and hand gestures for large-scale display," in CHI'10 Extended Abstracts on Human Factors in Computing Systems, 2010, pp. 3709-3714.

[8] S. Abrahão et al., "User experience for model-driven engineering: Challenges and future directions," in ACM/IEEE 20th International Conference on Model Driven Engineering Languages and Systems (MODELS) (pp. 229-236). IEEE., 2017.

[9] J. O. Borchers, "A pattern approach to interaction design," in Proceedings of the 3rd conference on Designing interactive systems. processes, practices, methods, and techniques, 2000, no. 369-378, p. techniques.

[10] A. Jameson, "User modeling meets usability goals.," in In International Conference on User Modeling, 2005, pp. 1-3. 